\title{
Inquietações sobre gênero e sexualidade em espaços formativos: o caso do Pibid de Ciências ${ }^{1}$
}

\author{
Marcos Lopes de Souza ${ }^{2}$ \\ Anderson Ferrari ${ }^{3}$
}

\begin{abstract}
RESUMO
Neste artigo enfocamos os incômodos sobre gênero e sexualidade apresentados por participantes de um subprojeto do Pibid de Ciências dos anos iniciais do ensino fundamental de uma universidade federal mineira. O grupo era composto por professoras dos anos iniciais do ensino fundamental, licenciandas/os dos cursos de pedagogia, biologia, química e física e uma docente universitária da área de ensino de ciências. As inquietações trazidas pelo grupo nos encaminharam para perceber os investimentos feitos para o controle da sexualidade das crianças e o quanto a escola ainda tem se silenciado diante dos debates sobre sexualidade e quando opta por trazê-la, nas aulas de ciências, o enfoque ainda tem sido o da reprodução.
\end{abstract}

PALAVRAS-CHAVE: Formação docente. Ciências naturais. Ensino fundamental. Gênero. Sexualidade.

Concerns about gender and sexuality in formative spaces: the case of the PIBID of science education

\begin{abstract}
In this article we focus on the annoyances about gender and sexuality presented by participants of a sub - project of the Pibid of Sciences of the initial years of elementary education of a federal university in. The group
\end{abstract}

\footnotetext{
${ }^{1}$ Este trabalho foi desenvolvido durante o estágio de pós-doutorado realizado na Universidade Federal de Juiz de Fora (UFJF) com a supervisão do Prof. Dr. Anderson Ferrari. Apoio: FAPESB/CAPES. O resultado deste trabalho tem sido lastro para o desenvolvimento de análises do Projeto "Saberes sobre corpo, gênero e sexualidades em manuais escolares/livros didáticos de Biologia - Brasil/Portugal" - Chamada universal 01/2016 - CNPQ/MCTI.

${ }^{2}$ Doutor. Universidade Estadual do Sudoeste da Bahia (UESB), Jequié, Bahia, Brasil. E-mail: markuslopessouza@gmail.com.

${ }^{3}$ Doutor. Universidade Federal de Juiz de Fora (UFJF), Juiz de Fora, Minas Gerais, Brasil. E-mail: aferrari13@globo.com.
} 
consisted of teachers from the initial years of elementary education, graduates of the courses of pedagogy, biology, chemistry and physics and a university professor in the area of science education. The group's concerns led us to realize the investments made to control the sexuality of the children and how much the school still has been silenced in the debates about sexuality and when it chooses to bring it, in science classes, the focus has still been on reproduction.

KEYWORDS: Teacher education. Natural sciences. Elementary education. Gender. Sexuality

\section{Introdução}

Propositalmente escolhemos trazer no título deste texto a palavra "inquietação" para dizer dos sentidos que nos moveram nesta pesquisa e na organização da escrita, associando inquietação com incômodo, com algo que nos move em direção ao pensamento, a formação do pensamento ligada a constituição dos sujeitos. Como nos convida a pensar Márcio Alves da Fonseca (2004):

Em que medida o pensamento, para inquietar-se, precisa ser incomodado? Em relação a inúmeras filosofias talvez fosse possível afirmar, sem muito equívoco, que o pensamento, para inquietar-se, quase sempre precisa ser incomodado, ou ainda, que quanto mais o pensamento for incomodado, tanto mais poderá vir a inquietar-se. Neste sentido, uma interrogação acerca da relação entre a inquietação do pensamento e alguma forma de incômodo que estaria em sua causa ou origem pode ser interessante (p. 47).

Podemos dizer que estamos incomodados com a formação docente no que diz respeito às relações de gênero e sexualidade. E este incômodo nos inquieta em direção a pesquisa, a problematizar o pensamento, numa 
perspectiva foucaultiana. Além disso, é nessa linha de ação que queremos conduzir esse texto, ou seja, que ele também inquiete e convide a problematização do pensamento para pensar o que acontece com as relações de gênero e sexualidade quando um grupo de professoras e graduandas/os começam a discutir seus significados? Que formas de ensinar e aprender entram em cena quando se discute gênero e sexualidade? Acreditamos que existe alguma relação entre incômodos, inquietações do pensamento e a perspectiva foucaultiana a partir da ideia de problematização. Para Foucault:

problematização não quer dizer representação de um objeto preexistente, nem criação pelo discurso de um objeto que não existe. Problematização é o conjunto das práticas discursivas ou não discursivas que faz com que algo entre no jogo do verdadeiro e do falso, jogo que o constitui como objeto para o pensamento (seja sob a forma da reflexão moral, do conhecimento científico ou da análise política, etc). (FOUCAULT, 2006, p. 670).

Inspirados pela citação acima podemos dizer que problematizar significa remeter algo, seja pensamento, uma situação ou mesmo a construção do conhecimento científico para o "jogo do verdadeiro e do falso", ou seja, é tirar do lugar, desestabilizar e movimentar este algo. É transformar em problema de investigação o que comumente não nos incomodava para colocar sob suspeita nossas formas de pensar e agir, questionar o que somos e pensamos. Por isso assumimos como perspectiva de investigação e de organização deste artigo a problematização que nos remete a inquietação do pensamento.

Para isso vamos trazer o campo empírico de um estudo realizado na Universidade Federal de Juiz de Fora (UFJF), no ano de 2014, inquietados pelo argumento muito utilizado por docentes e também licenciandas e licenciandos: a suposta ausência de espaços formativos que priorizem os 
debates sobre gênero e sexualidade. Partimos do pressuposto de que os cursos de formação inicial e continuada, mesmo quando não apresentam componentes curriculares que tratam dessas questões, ensinam continuamente sobre gênero e sexualidade de diferentes maneiras como, por exemplo, nas feminilidades e masculinidades que são reiteradas nas relações construídas na comunidade universitária e na própria generificação dos espaços das instituições de ensino superior.

Diante disso, esta pesquisa ocorreu em espaço de formação inicial, um subprojeto do Programa Institucional de Bolsas de Iniciação à Docência (Pibid) da UFJF na cidade de Juiz de Fora-MG. O subprojeto Pibid Interdisciplinar Ciências I estava ligado aos anos iniciais do ensino fundamental e era formado, na época, por uma coordenadora, três supervisoras (professoras das séries iniciais) e 15 estudantes de diferentes cursos: Pedagogia, Licenciatura em Química, Física e Biologia.

O Pibid é um programa do governo federal com o objetivo de aprimorar a formação de professores(as) da educação básica e, por sua vez, a qualidade do ensino no país considerando a necessidade de fortalecer a relação entre universidade e escola e as vivências em sala de aula. Este programa disponibiliza bolsas para estudantes dos cursos de licenciatura que participam dos projetos de Pibid desenvolvidos pelas instituições de ensino superior (IES) em parceria com as escolas públicas de educação básica do Brasil. As/os docentes das escolas e da universidade envolvidas/os nos projetos também são contempladas/os pelas bolsas. As IES que desejam ter projetos vinculados ao Pibid devem apresentar suas propostas junto à Coordenação de Aperfeiçoamento de Pessoal de Nível Superior (Capes) conforme as publicações dos editais de seleção (BRASIL, 2010).

O Pibid Interdisciplinar de Ciências tinha encontros semanais. No primeiro dia que fomos na reunião do grupo, apresentamos a proposta da pesquisa e consultamos sobre a participação e o consentimento do grupo. Após todas e todos concordarem, acompanhamos os encontros no período de outubro de 2014 a março de 2015. Em alguns momentos fizemos 
intervenções pontuais e, além disso, em dois encontros trabalhamos com as questões de gênero e sexualidade. Em um deles foi feita uma discussão com base em depoimento de docentes e discentes sobre gênero, sexualidades e educação escolar obtidos junto ao trabalho de Abramovay, Castro e Silva (2004) e no outro foi trabalhado o curta metragem Vestido Nuevo4, seguido de debate sobre este artefato articulando com as questões sobre diversidade de gênero e sexual no espaço escolar. Esses dois encontros foram gravados em áudio e, posteriormente, transcritos. Nos demais encontros, utilizamos o diário de campo como ferramenta de produção de informações.

Neste trabalho nos enveredamos pelo caminho dos estudos pósestruturalistas ao duvidar do nosso olhar muitas vezes cristalizado já que o que vemos e como vemos é construído culturalmente; contestar as explicações totalizantes, universalizantes e deterministas; trilhar caminhos sem um destino prévio, abertos ao inesperado, sem saber onde chegaremos; trabalhar com análises provisórias, singulares e relacionadas ao contexto em que a investigação se desenhou; caminhar com os referenciais que elegemos mas também desconfiar deles e apostar nos regimes de verdade que nos produzem e que podemos continuamente contestar (MEYER; SOARES, 2005).

Para o desenvolvimento deste texto, elegemos como foco de problematização a seguinte questão: que indagações e incômodos envolvendo gênero, sexualidade e educação são suscitados durante as discussões desenvolvidas junto ao espaço formativo do Pibid Interdisciplinar de Ciências dos anos iniciais do ensino fundamental? Queremos tomar essa questão buscando a provisoriedade das conclusões para apontar algumas leituras dessas inquietações, recorrendo, para isso, a alguns trechos de falas das(os) participantes em um dos encontros em que discutimos sobre gênero e sexualidade.

\footnotetext{
4 "Vestido Novo" é um curta metragem de produção espanhola de 2007, dirigido por Sergi Pérez. A narrativa diz da história do menino Mário, uma criança que vive momentos de preconceito na escola e acaba indo para a direção. Durante uma atividade de carnaval, Mário decide ir de vestido rosa para escola, incomodando professora e alunos/as.
} 


\section{Os investimentos no controle da sexualidade das crianças}

Vamos partir do princípio que os espaços formativos são convites para que possamos trazer histórias, vivências, experiências que coletivamente são discutidas e nos permitem entrar em contato com nossas formas de pensar e agir. Com o grupo do Pibid não foi diferente, sobretudo por que estavam nas escolas, local de negociação, de confronto e do imprevisível, mas também da disciplinarização dos corpos, desejos e prazeres. Como nos lembra Foucault (1988) quando nascemos já encontramos um mundo organizado discursivamente, o que nos faz sermos muito mais resultado destes discursos do que propriamente produtores deles. Somos sujeitos de experiência que diz de certa tensão entre saber-poder-subjetividades, que nos constitui. Quando provocamos com a discussão das relações de gênero e sexualidade partimos do reconhecimento de que somos seres pensantes, "sendo o pensamento não aquilo que nos faz acreditar no que pensamos ou admitir o que fazemos, e sim o que nos faz problematizar aquilo mesmo que somos" (FONSECA, 2004, p. 48-49). Com isso queremos deixar claro que não estamos acionando as falas das/os participantes no sentido de denunciar o mal que está presente em tudo o que existe, mas para colocar sob suspeita o perigo daquilo que é tido como comum, normal, natural, sólido e que nos constitui como "verdade".

Desta forma, uma das questões que nos inquietou foi sobre uma situação relatada por uma das professoras no primeiro dia em que participamos dos encontros e que foi retomada, pela mesma professora, no dia em que fizemos uma discussão mais detalhada sobre gênero e sexualidade, revelando sua inquietação. Quando propusemos debater a presença das relações de gênero e sexualidade nas escolas, são as inquietações e os incômodos que vêm à tona. Inquietações e incômodos que só podem ser entendidos nesta expressão porque dizem dos saberes que nos constituem e que, de alguma maneira, são contestados. Contava ela que um de seus alunos era muito paquerado pelas meninas e isso a incomodava: 
"O Henrique recebeu um bilhete de uma garota dizendo que ela aceitava namorar com ele, mas com ela seria diferente. Ela queria passear, conversar e não ia brigar como a outra. O pior que ele é bonito mesmo e as meninas ficam assanhadas. Eu falei que criança de 8 anos pega no caderno, no lápis e não pega ninguém. Mas, eles namoram, mas não é namoro como na nossa época de dar a mão e tal, é namoro de ficar beijando, de ficar colocando a mão. Eu já cortei se não vira algazarra" (Letícia5 - professora dos anos iniciais do ensino fundamental).

Quais são os incômodos que organizam a narrativa e a compreensão dos sujeitos e do fato? Como esses incômodos dão lugares para os sujeitos, seus corpos e desejos? Podemos sugerir que são alguns os incômodos que dão lugar a professora na sua ação de educar. Um primeiro diz da ação da menina em dizer do seu desejo, ou seja, é a menina que manda um bilhete para Henrique. No entanto, é ela quem também define o que é namoro, ou minimamente o que ela deseja como namoro, marcando uma diferença entre ela e as demais meninas. Essa marcação da diferença entre ela e as demais meninas e do seu entendimento de como deve se relacionar com o menino também nos diz da impossibilidade de pensar essas relações como homogêneas e mesmo de tratar a categoria menina como algo natural, essência e homogênea. Jane Felipe (1999) nos mostra como as hierarquias de gênero são contestadas e mantidas por meninos e meninas nos ambientes em que circulam, como a escola. A ação da menina invoca e diz da ação e constituição da professora como uma mulher, que está no exercício de educar os sujeitos, principalmente em se tratando da recuperação deste fato num ambiente de formação como o Pibid em que dizer da sua ação é ensinar a ser professora. Podemos pensar que as relações de gênero dizem da ação dos sujeitos sobre os outros e sobre si mesmos. Gênero, segundo Joan Scott (1995) deve ser compreendido como um organizador das relações sociais, de maneira que a ação da professora não diz somente na transmissão de conteúdo, mas na constituição de sujeitos de um determinado gênero. Uma

\footnotetext{
5 Todos os nomes que aparecerão no texto são fictícios, resguardando o anonimato. Tanto os nomes dos e das participantes do grupo Pibid quanto dos nomes que eventualmente aparecerão nas falas.
} 
ação que confirma o gênero como fundado nas diferenças entre o que cabe a meninos e a meninas. Ela afirma: "O pior que ele é bonito mesmo e as meninas ficam assanhadas". O fato de ter a beleza reconhecida como uma qualidade não é suficiente para absolver as meninas. Ela como mulher também admite que homens bonitos podem atrair mulheres. No entanto, ela também tem uma ação sobre o que cabe as meninas, construindo o que é ser mulher, de maneira que o fato de ser bonito não absolve as meninas, que sofrem um controle na classificação de "assanhadas".

"Eu já cortei se não vira algazarra”. A ação sobre a menina é uma ação sobre si mesma, entendendo como função do "ser professora" o controle sobre as ações, os corpos e desejos. Além disso o entendimento do espaço escolar como aquele da disciplina e não da "algazarra" contribui para o entendimento de que como deve agir. Mesmo que não reconheça que está trabalhando com a construção das relações de gênero, a ação da professora é organizada por entendimentos do que é ser menino e menina, de determinada idade na escola. Podemos pensar que o ser menina e mulher se constrói da relação entre os gêneros, ou seja, na negação do que é ser menino e homem, mas também no interior do próprio gênero pela ação das mulheres sobre as meninas. O gênero pode ser entendido como uma experiência constitutiva dos sujeitos (SCOTT, 1995), visto que ele diz da construção social que uma cultura estabelece para as relações entre meninos e meninas. E continua ela.

"Realmente hoje, os adolescentes não estão tendo muita consciência do que eles estão fazendo. Por exemplo, no passeio que nós fomos na quinta-feira, tinha uma professora na frente, duas no meio e eu atrás e de repente eu escutei uma confusão. O que foi gente? E falei com a Renata, o que está acontecendo? Aí ela pegou e falou assim: É a Cintia que tá sarrando com o Henrique, sentando no colo dele, sarrando ele. Eu nem sabia que existia mais essa palavra sarrar. Achei que fosse da minha época. E aí vira a outra professora mais velha falou: Ué, sarrar é mexer. Ela tá xingando ele? Eu comecei a rir. Aí eu chamei Henrique: Henrique vem sentar aqui perto de mim! O Henrique é lindo. As meninas quando elas olham ele, elas ficam loucas, entendeu? Eu fiquei tão chocada com essa história de estar sarrando. Aí ele falou: Não tia, 
a gente estava fazendo pulseirinha. Aí eu coloquei ele para trás porque onde ele vai as meninas atacam ele. E o pai dele diz que gosta que ele namora (Letícia).

Seguindo a mesma linha de estranhamentos da professora que associa a sexualidade a faixa etária, podemos perceber a tentativa de dessexualizar as crianças reforçando a inquietação pelo fato das crianças, por serem muito jovens, desejarem namorar entre si, o que para ela é inconcebível já que as crianças devem estudar, como ela mesmo diz, e não pegar ninguém. "A tentativa de dessexualizar as crianças é um fenômeno recente na história ocidental, pois até meados do século XVII meninos e meninas conviviam com o mundo adulto em todas as suas nuances" (FELIPE, 2003, p. 58). Um fenômeno que não tem nada de natural, mas é fruto da construção discursiva que nos faz negar a sexualidade e os desejos na infância. Ela volta a reforçar a beleza do Henrique como causadora de algo incontrolável: "O Henrique é lindo. As meninas quando elas olham ele, elas ficam loucas, entendeu?" Ela parece ter incorporado o discurso que vários campos do conhecimento têm construído sobre os corpos e desejos dos sujeitos. Discursos que a constituem no lugar da professora que age para disciplinar e controlar os desejos: "Henrique vem sentar aqui perto de mim!" Ou ainda: "Aí eu coloquei ele para trás porque onde ele vai as meninas atacam ele". Ao mesmo tempo em que a escola investe numa educação do controle da sexualidade entre meninos e meninas, esta ação encontra reforço, ou é contestada pelas outras instituições de educação como a família, por exemplo. Buscando educar no interior do gênero, o pai investe no seu entendimento do que é ser homem, que admite a expressão da sexualidade como constituidora do ser homem, na medida em que ela se enquadre na heteronormatividade. Isso chega a escola e entra em negociação com o que a professora faz: "E o pai dele diz que gosta que ele namora".

Além de questionar o namoro, ela também se inquieta com a forma que eles namoram, incluindo os beijos, por exemplo. Diferente da época dela e das outras colegas professoras em que namorar era dar as mãos, hoje, para 
Letícia, as crianças estão exagerando, indo além do que é desejável. Há um saudosismo das relações de décadas atrás. Recuperar sua constituição é uma forma de justificar sua ação, de maneira que agir sobre suas alunas é uma maneira de reforçar sua história de vida e sua forma de ser. Na medida em que a sexualidade foi se constituindo como um grande sistema de interdição ela passou a despertar o interesse das instituições e das pessoas (FOUCAULT, 1988). Como sistema de interdição que não mais produz do que nega, a sexualidade nos incita a falar de nós mesmos, a partir dos nossos desejos e as relações de verdade do sujeito. Como no ensina Foucault (1988), as proibições advindas da sexualidade estão diretamente relacionadas a obrigação de confessar e dizer a verdade sobre si mesmo. $\mathrm{O}$ entendimento de que as crianças e adolescentes não têm ou não deveriam ter sexualidade está atrelado ao pensamento de que a sexualidade é uma exclusividade da vida adulta e que, portanto, deve-se investir no silenciamento dessas questões para as crianças e no adiamento das conversas sobre sexualidade para o chamado momento certo que, geralmente, está associado ao conceito de maioridade dos dias atuais, ou seja, após os 18 anos.

$\mathrm{Na}$ cena em que a professora anuncia seus estranhamentos quanto à sexualidade das crianças, uma questão que nos chamou atenção foi o incômodo de Letícia ao ver que as meninas estavam paquerando o garoto, ou seja, não era apenas a idade das crianças que a afligia, mas a atitude das garotas. Por que nos incomoda ver a menina escrevendo o bilhete e entregando ao garoto? Por que, quando e como a atitude da menina, classificada como "assanhada" se tornou um problema? E vai de um investimento no controle da sexualidade, desde a infância a fase adulta que se dirige, sobretudo, às mulheres. A construção do que é ser mulher diz também como ela deve entender e lidar com a sua sexualidade, tanto que, não é por acaso que as mulheres, mesmo com os avanços das lutas feministas, ainda são permanentemente produzidas para conter sua sexualidade perante a sociedade. 


\section{O que a escola (não) fala sobre sexualidade?}

Em se tratando de um grupo de formação como Pibid em que a escola é o grande objeto de intervenção, a discussão logo tomou a problemática dessas questões no que tange ao trabalho atribuído a escola e às(aos) professoras(es). Um primeiro conjunto de posicionamentos foi construído pelas falas das licenciandas e dos licenciandos que faziam parte do grupo. Ao mesmo tempo em que reconhecem as ausências da escola no trabalho com as relações de gênero e sexualidade a partir de suas trajetórias escolares, também tomam essas experiências para se pensarem como futuros professores e professoras.

"Isso aí de que a escola explica isso, eu nunca tive isso. Nunca tive essa explicação. A única professora que explicou alguma coisa sobre isso eu estava na $6^{\text {a }}$ série. Todo mundo morrendo de vergonha de perguntar. A gente sentou em círculo assim. O que os meninos faziam? Eu como sempre nunca tive vergonha de perguntar nada, eles passavam o papelzinho pra mim, eu perguntava em voz alta. Ela explicava. Mas foi a única vez. $\mathrm{Na}$ sétima, oitava, primeiro ano, segundo eu nunca tive explicação mais de nada. Mas foi uma explicação muito básica, eu tinha 12 anos de idade. Ela não entrou muito também a fundo" (Bianca Licencianda do curso de Química).

"Mas se você entra neste tipo de assunto e o aluno chega em casa contando para os pais aí chega na escola e vai brigar porque o professor está ensinando pro meu filho isso, isso e isso" (Daniela Licencianda do curso de Pedagogia).

"Eu tive isso desde a $4^{\mathrm{a}}$ série com uma professora muito louca e ela falava pra gente na $4^{a}$ série. Criança tem muita dúvida e menos vergonha de perguntar e realmente isso ajudou muito a gente" (Mateus - Licenciando do curso de Biologia).

Três falas de três estudantes de cursos distintos: Química, Pedagogia e Biologia. Falas que recordam o momento de formação na escola. Mateus e Bianca dizem de um certo prazer quando o tema da sexualidade foi tratado. Ao mesmo tempo que Bianca revela a "vergonha" que marcou esse dia, ela 
demonstra a relação de poder que atravessou essa aula e sua participação. Ela se coloca numa outra relação com a turma, "Eu como sempre nunca tive vergonha de perguntar nada, eles passavam o papelzinho pra mim, eu perguntava em voz alta”. Falar de sexualidade é falar de relação de poder, como nos convoca a pensar Michel Foucault (1988). Ao afirmar que nunca teve vergonha de nada, Bianca se coloca a frente da turma, estabelece com as/os demais uma relação em que ela era mais avançada, mais esperta, fornecendo a ela um lugar naquela ocasião e agora ao relembrar tal fato. Por isso, falar de sexualidade está inscrita numa causa política. "E a causa do sexo - de sua liberdade, do seu conhecimento e do direito de falar dele encontra-se, com toda legitimidade, ligada às honras de uma causa política: também o sexo se inscreve no futuro" (FOUCAULT, 1988, p. 11-12).

Esse sentido de si a partir da participação é construído pelo teor de proibido que ronda o tratamento com as sexualidades nas escolas. E isso está posto nos sujeitos, de tal forma que ela, a licencianda, não somente assume seu protagonismo e fala alto, enquanto as/os outras/os tinham vergonha de escrever perguntas no papel. Ela fortalece seu lugar de vanguarda e é capaz de avaliar o trabalho que foi feito. Diz ela: "Mas foi uma explicação muito básica, eu tinha 12 anos de idade. Ela não entrou muito também a fundo". Mas a escola tem seus encantos. A experiência ficou de tal modo presente que ela é capaz de lembrar e de estabelecer uma comparação com sua trajetória escolar no trabalho com as sexualidades. "A única professora que explicou alguma coisa sobre isso eu estava na $6^{a}$ série". Uma única professora. Recorrendo a ideia de experiência em Larrosa (2002), podemos dizer que experiência é algo que nos toca, que nos acontece, que nos marca. Porque o trabalho com as sexualidades nos marca? Talvez por que esteja inscrito neste sistema de repressão e incitação a falar.

Não por acaso, Mateus também se lembra da sua professora, aquela que ousou falar de sexualidade. E foi algo de tal forma marcante que ele fornece um adjetivo para a professora - "uma professora muito louca" - o 
que significa colocar essa professora neste lugar? Qual a relação desta classificação com o fato dela ter tratado o tema da sexualidade?

Existe, talvez, uma outra razão que torna para nós tão gratificante formular em termos de repressão as relações do sexo e do poder: é o que se poderia chamar o benefício do locutor. Se o sexo é reprimido, isto é, fadado à proibição, à inexistência e ao mutismo, o simples fato de falar dele e sua repressão possui como que um ar de transgressão deliberada. Quem emprega essa linguagem colocase, até certo ponto, fora do alcance do poder; desordena a lei; antecipa, por menos que seja, a liberdade futura. Daí essa solenidade com que se fala, hoje em dia, do sexo (FOUCAULT, 1988, p. 12).

A ideia do "benefício do locutor", associando repressão, liberdade e futuro ainda hoje está presente nas relações entre professor/a-aluno/a. Mateus recupera a sensação de incerteza e associa essa aula em que as dúvidas surgiram como de grande proveito para a formação dos alunos e alunas: "Criança tem muita dúvida e menos vergonha de perguntar e realmente isso ajudou muito a gente". Sala de aula é o lugar em que vamos tentando afastar as dúvidas, seja na intenção de evitar os imprevistos que povoam as aulas, seja dando lugar a elas para que se acabem. Para Deborah Britzman (2007) a sexualidade não é o problema, mas sim o lugar em que os problemas se afixam, mas ao mesmo tempo, ela é organizada por um modo de pensamento que é a curiosidade, que tem como característica ser um modo de pensamento que não aceita a segurança.

A dúvida é o lugar da curiosidade, que se movimenta em direção ao pensamento imprevisto, aquele que não está ancorado na segurança e que demonstra que o conhecimento é sempre insuficiente. A curiosidade será sempre realimentada. 
A cultura da escola faz com que respostas estáveis sejam esperadas e que o ensino de fatos seja mais importante do que a compreensão de questões íntimas. Além disso, nessa cultura, modos autoritários de interação social impedem a possibilidade de novas questões e não estimulam o desenvolvimento de uma curiosidade que possa levar professores e estudantes a direções que poderiam se mostrar surpreendentes. Tudo isso faz com que as questões da sexualidade sejam relegadas ao espaço das respostas certas ou erradas (BRITZMAN, 2007, p. 85-86).

Poder se expressar através da curiosidade e ter o espaço de acolhimento parece ter sido importante para Mateus e Bianca. Uma ação das professoras que parece ter possibilitado novas práticas do eu a partir do conhecimento. Mas enquanto Mateus e Bianca recorrem as suas experiências para falar da positividade do trabalho com as sexualidades, Daniela se coloca como professora diante do desafio atual, de controle e intervenção das famílias quando o assunto é a sexualidade: "Mas se você entra neste tipo de assunto e o aluno chega em casa contando para os pais aí chega na escola e vai brigar porque o professor está ensinando pro meu filho isso, isso e isso". O que parece importante para alguns torna-se algo arriscado para outros. Fazendo o encontro entre essas três falas e três posicionamentos podemos pensar que o problema consiste em saber qual conhecimento possibilitará aos alunos e às alunas se pensarem a partir de outras práticas em um momento no qual a sexualidade está sendo entendida como discursos do pânico moral? Como fica a curiosidade e o convite a expressar os entendimentos que nos constituem num momento em que a suposta proteção de crianças inocentes está servindo para calar? A professora supervisora Rute nos diz que:

"Acho que hoje pela sexualidade estar mais aflorada é que realmente a gente tem que saber trabalhar. No $5^{\circ}$ ano quando a gente começa a trabalhar Reprodução, a gente faz um apendicizinho para trabalhar sexualidade na escola. Só que antes disso, na reunião de pais anterior que tenha isso, a gente pega a 
autorização por escrito dos pais. A gente dá uma palestra para os pais, apresentando o que vai ser dito para os alunos e os pais autorizam ou não. Aí naquela semana que a gente vai fazer esse tipo de trabalho, a criança que o pai não autorizou, ela não vai, se ela for, ela vai pra outra atividade. E aí o que está acontecendo? Aí vem aumentando a cada dia o número de alunos que vão para outra sala. Os pais não deixam. A mídia tá mostrando, tá apresentando uma coisa que não é a realidade, o pai não tá falando em casa e ainda proíbe que a escola faça isso" (Rute professora dos anos iniciais do ensino fundamental).

$\mathrm{Na}$ fala de Rute chama-nos atenção o lugar em que a sexualidade é abordada na escola. Embora saibamos que essas questões atravessam a escola e, muitas vezes, de maneira imprevista e advindas do desejo dos/as estudantes, no momento em que a escola resolve destinar um determinado momento para discutir sobre isso, mesmo que seja pontual, aparece quando se trabalha com reprodução e, mais do que isso, entra como um apendicizinho. Quais as implicações em se trabalhar com sexualidade sendo que a temática que traz este debate é a reprodução? $\mathrm{O}$ que significa trabalhar sexualidade como um apêndice no currículo?

Como já mencionado no início do texto, as três professoras supervisoras do Pibid lecionavam nos anos iniciais do ensino fundamental e, neste nível de ensino, elas trabalhavam com vários conteúdos específicos, incluindo o de Ciências. De alguma forma, com o relato de Rute parece que ainda persiste em suas aulas de Ciências para os anos iniciais, o discurso das ciências naturais, especialmente, o da biologia que direciona a sexualidade para a reprodução. A sexualidade reprodutiva parece ser aquela que tem uma maior legitimidade, pois é vista como natural, reiterando o discurso biológico de que o propósito de uma relação sexual é gerar descendentes para a chamada manutenção da espécie, independente das escolhas dos sujeitos, legitimando o casal heterossexual procriador e o que foge a isso, inclusive os estéreis, se tornam anormais (FOUCAULT, 1988).

Conforme trazido por Furlani (2003), quando a sexualidade é tratada com base nareprodução valoriza-se uma determinada prática sexual (sexo vaginal), desprezando a masturbação e outras práticas (como o sexo oral e 
anal) mesmo que ocorram entre homem e mulher; diminui-se a relação entre a sexualidade e o prazer em prol do objetivo de se ter filhas(os); ratifica-se a ideia de que apenas as pessoas em uma idade propícia à reprodução é que teriam uma vida sexual ativa, desconsiderando, sobretudo, as(os) idosas(os) e favorece-se um determinado modelo de família formada por um homem, uma mulher e as(os) filhas(os). Além disso, quando se prioriza a relação entre reprodução e sexualidade, reitera-se a heterossexualidade como expressão natural e intrínseca do ser humano, marginalizando as relações sexuais e afetivas entre pessoas do mesmo sexo.

Os próprios livros didáticos de Ciências dos anos iniciais do ensino fundamental há algum tempo também associam a ideia de sexualidade com a reprodução. Ribeiro e Marques (2009) analisaram os corpos apresentados em dez livros de Ciências dos anos iniciais do ensino fundamental utilizados por professoras dos anos iniciais de escolas do município de Rio Grande/RS. Além de evidenciarem um determinado modelo de corpo universal e hegemônico, geralmente nos livros de segundo ano dos anos iniciais, as genitálias estão tapadas enquanto nos de quinto ano são evidenciadas as diferenças entre as genitálias de meninas e meninos como pertencentes ao chamado "sistema reprodutor".

Historicamente, o ensino da sexualidade na escola foi atrelado à disciplina de Ciências e Biologia. Este era um dos espaços curriculares em que se falava mais sobre sexualidade, de tal maneira que docentes de outras áreas do conhecimento não se sentiam encarregadas(os) e muito menos preparados(as) para trabalhar com essas questões já que havia uma certa autoridade por parte de quem era formada(o) em Ciências Biológicas. Com isso, a sexualidade construída nos currículos escolares foi associada ao ensino das ciências naturais e marcada pelo discurso médico e biológico em que a reprodução ganha maior legitimidade e com ela, alguns conhecimentos são reconhecidos como prioritários, tais como: as genitálias, gametas, ciclo menstrual, gravidez, gestação, parto, infecções sexualmente transmissíveis e contracepção (ALTMANN, 2007; AZEVEDO; SOUZA, 2016). 
Outro aspecto trazido pela professora Rute refere-se à necessidade da autorização da família para que o/a filha/filho possa participar das atividades sobre sexualidade que ela desenvolve. Inclusive antes de solicitar esta permissão, ela explana aos familiares quais questões abordará com seus/suas alunos/alunas. E mais do que isso, caso a família não autorize haverá outras atividades para aquela criança. Mas, o que a professora destaca é o aumento de crianças não consentidas a assistir as aulas sobre sexualidade, evidenciando uma possível desautorização da escola em dialogar sobre esta temática e em um fortalecimento da família e de outras instituições, em especial as religiosas, em assumir exclusivamente para si esses debates.

A sexualidade ainda é uma questão que apavora ou gera receio por parte de muitos familiares já que alguns/algumas acreditam que ao se trabalhar com essas discussões haverá um incentivo para que as(os) filhas(os) iniciem sua vida sexual mais cedo do que desejam, algo que preferem adiar o máximo que puderem e para alguns apenas após o casamento.

Nos últimos anos, especialmente durante a aprovação da retirada das questões de gênero e sexualidade do Plano Nacional de Educação (PNE) para o decênio 2014-2024, houve um movimento liderado por grupos conservadores cristãos que geraram um pânico social em torno do que nomeiam de "ideologia de gênero". Conforme os discursos difundidos por esses grupos, as escolas ao falarem sobre gênero e sexualidade estariam abalando a família tradicional, perturbando a ideia natural e cristã do que é ser homem e mulher e transformando as crianças em gays, lésbicas e transgêneros.

Castro e Ferrari (2017) evidenciam esta tensão entre os estudos de gênero e sexualidade, movimentos sociais e as instituições religiosas que constroem verdades sobre gênero e sexualidade e as disputam nessas relações de saber e poder, acirrando cada vez mais o debate. Segundo os autores, alguns grupos religiosos cristãos constroem discursos com base nos 
fundamentos restritos bíblicos, produzindo determinados valores e modos de vida cisheteronormativos a que devem seguir todos os sujeitos considerados normais. Ao mesmo tempo em que defendem essa verdade, contestam a "ideologia de gênero" e difundem esses discursos na sociedade, especialmente nas redes sociais, nas igrejas e entre as famílias, criando um movimento em prol dos valores tradicionais cristãos e contrários aos debates sobre diversidade de gênero e sexual na escola.

Portanto, quando Rute diz que muitas famílias não querem que suas/seus filhas/filhos tenham aulas ou discussões sobre sexualidade na escola, isto também tem sido potencializado por esses movimentos conservadores que consideram os debates escolares como ameaçadores da educação familiar cristã e que, portanto, ao tratar dessas temáticas, a escola estaria contrariando os valores ensinados nesses ambientes familiares. De forma geral, mesmo que muitas vezes a escola construa verdades que se apoiem em discursos cisheteronormativos, seu lugar de instituição com autoridade para dialogar sobre sexualidade tem sido posto em xeque e, com isso, a vigilância em torno do trabalho das professoras, como foi o caso de Rute, se intensifica.

Para além disso, mesmo em se tratando de falar sobre sexualidade nas aulas de ciências com base na reprodução, ainda assim, muitos/as desejam que essas questões não sejam tratadas, pois estaríamos incentivando as/os estudantes a iniciarem sua vida sexual, algo indesejável para os grupos convervadores.

\section{Considerações Finais}

$\mathrm{Na}$ convivência com as professoras dos anos iniciais do ensino fundamental que acompanhamos nos encontros do PIBID de Ciências, uma das questões trazidas por elas como inquietantes era perceber que algumas de suas alunas desejavam namorar um garoto que chamava a atenção de muitas delas. A princípio pensamos que se tratava apenas do fato de serem 
crianças e por isso, elas e tantas/os outras/os docentes desejavam adiar esse debate para outro momento, quando fossem mais velhas. Todavia não era apenas isso, mas pela atitude partir de uma garota o que contesta as normas hegemônicas de gênero. Essas questões nos encaminharam para pensar sobre como ainda se investe no controle da sexualidade das mulheres desde quando elas ainda são garotas.

Além disso, outra questão trazida por esta pesquisa foi sobre o ensino da sexualidade na escola. De um lado as/os licenciandas/os reiteram que foram poucos os momentos de diálogo que tiveram na educação básica e, mesmo quando foi abordado buscou-se a superficialidade. Já as professoras dizem que em suas aulas de ciências abrem um apêndice para essas discussões, mas com o eixo da sexualidade reprodutiva. Talvez isto nos mobilize a pensar que esta perspectiva da sexualidade pautada no sistema genital e na reprodução ainda seja muito potente no discurso das ciências naturais, havendo poucos espaços legitimados para outros debates. E mesmo com esse discurso, algumas famílias rejeitam esses debates na escola. Estamos diante de um enfrentamento que não se acabou e que nos provoca a pensar: quais sexualidades queremos debater nas aulas de ciências do ensino fundamental? A questão está em aberto.

\section{Referências}

ABRAMOVAY, M.; CASTRO, M. G.; SILVA, L. B. Juventudes e Sexualidade. Brasília: UNESCO Brasil, 2004.

ALTMANN, H. A sexualidade adolescente como foco de investimento político-social. Educação em Revista. Belo Horizonte. n. 46, p. 287-310, dez. 2007.

AZEVEDO, S. M. M. M.; SOUZA, M. L. O ensino da sexualidade em um componente curricular específico: regulações e escapes. Ensino em Re-Vista, Uberlândia, MG, v.23, n.2, p.367-386, jul./dez./2016.

BRASIL. Presidência da República. Decreto $\mathrm{n}^{\circ}$ 7.219, de 24 de junho de 2010. Dispõe sobre o Programa Institucional de Bolsas de Iniciação à Docência - PIBID e dá outras providências. D. O. U. de 25/06/2010. 
CASTRO, R. P.; FERRARI, A. A "ideologia de gênero" e processos educativos nos discursos religiosos: efeitos de saber-poder-verdade. In: FERRARI, A.; CASTO, R. P. (orgs.). Diversidades sexuais e de gêneros: desafios e potencialidades de um campo de pesquisa e conhecimento. Campinas, SP: Pontes Editores, 2017, p. 75-99.

BRITZMAN, Deborah. "Curiosidade, sexualidade e currículo", In: LOURO, Guacira Lopes (org.). O corpo educado: pedagogias da sexualidade, Belo Horizonte: Autêntica, 2007, p. 85-111.

FELIPE, Jane. Construindo identidades sexuais na Educação Infantil. Páteo, v. 7, p. 56-58, 1999.

. "Erotização dos corpos infantis". In: LOURO, Guacira et al. (org.). Corpo, gênero e sexualidade: um debate contemporâneo na educação. Petrópolis: Vozes, 2003, p. 54-66.

FONSECA, Márcio Alves da. "Do incômodo da imagem à inquietação do pensamento". Revista VERVE, n. 6, p. 47-58, 2004.

FOUCAULT, Michel. História da Sexualidade I: a vontade de saber. Rio de Janeiro: Edições Graal, 1988.

O cuidado com a verdade. In: MOTTA, Manoel de Barros da (org.). Ditos e Escritos $V$. Ética, sexualidade e política. 2 ed. Rio de Janeiro: Forense Universitária, 2006, p. 240- 251.

FURLANI, Jimena. Educação sexual: possibilidades didáticas. In: LOURO, Guacira et al. (org.). Corpo, gênero e sexualidade: um debate contemporâneo na educação. Petrópolis: Vozes, 2003, p. 67-82.

LARROSA, Jorge. Notas sobre a experiência e o saber da experiência. Revista Brasileira de Educação, Campinas, n. 19, p.20-28, 2002.

MEYER, D. E.; SOARES, R. F. Modos de ver e se movimentar pelos "caminhos" da pesquisa pós-estruturalista em Educação: o que podemos aprender com - e a partir de - um filme. In: COSTA, M. V.; BUJES, M. I. E. (orgs.). Caminhos investigativos III: riscos e possibilidades de pesquisar nas fronteiras. Rio de Janeiro: DP\&A, 2005, p. 23-44.

RIBEIRO, P.; MARQUES, M. Investigando os corpos nos livros didáticos de ciências dos anos iniciais do ensino fundamental. Revista Enseñanza de las Ciencias, número extra VIII Congreso Internacional sobre Investigación en Didáctica de las Ciencias, Barcelona, p. 970-974, 2009.

SCOTT, Joan. Gênero: uma categoria útil de análise histórica. Educação e Realidade, v. 20, n.02, p. 71-99, 1995. 